\title{
Deriving Measurement Strategies from Science
}

\author{
George J. Komar \\ NASA Earth-Sun System Technology Office \\ Greenbelt, MD 20771, USA \\ 301-286-0007 \\ George.J.Komar@nasa.gov
}

\author{
Amy L. Walton \\ NASA Earth-Sun System Technology Office \\ Greenbelt, MD 20771, USA \\ 301-286-9699 \\ Amy.L.Walton@nasa.gov
}

\begin{abstract}
Earth-Sun System activities within the National Aeronautics and Space Administration are science-driven and technology-enabled. NASA has developed a process for matching science needs and technologies that includes a set of notional mission concepts.

This document ${ }^{1,2}$ summarizes the most recent output of that process: a notional set of science objectives, technology requirements, and measurement/mission concepts stretching beyond the time horizon of current plans. The materials can be a valuable resource in efforts to sketch out the future of Earth-Sun science and applications from space.
\end{abstract}

\section{TABle OF Contents}

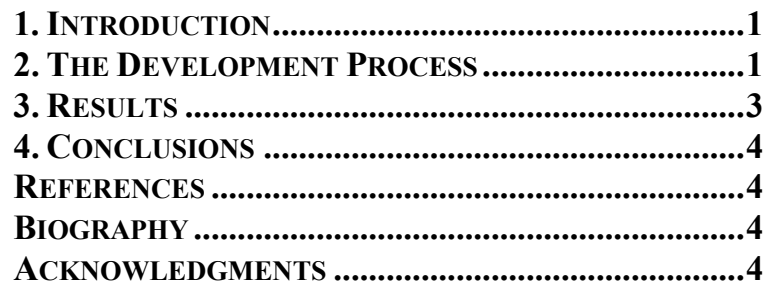

\section{INTRODUCTION}

The National Aeronautics and Space Administration (NASA) organizes its Earth-Sun System research into a set of seven interdisciplinary science focus areas for the purpose of creating and managing an implementable set of programs. The seven focus areas are:

- Atmospheric Composition

- Carbon Cycle and Ecosystems

- Climate Variability

- Earth Surface and Interior

- Sun-Solar System Connection

- Water and Energy Cycle

- Weather

The rationale for the current, specific set of science focus areas is contained in the Earth-Sun System Research Plan [1]. For each focus area, the Research Plan contains a roadmap for the period 2005-2014. Consistent with NASA's end-to-end approach to addressing science questions, each roadmap and supporting information encompasses science questions and research objectives, observations, major field campaigns, computational modeling, and scientific assessments.

Because of the five-year time horizon of the Federal budget process, and because of the long development time required for satellite missions, activities within the first 5-7 years of each roadmap are relatively firm, while later activities are more flexible and notional.

Whether near-term or farther in the future, Earth-Sun System activities within NASA are science-driven and technology-enabled. The search for answers to science questions that can best be addressed via remote sensing inevitably leads to discussions of potential approaches to acquiring the needed observations; this in turn leads to questions of technological feasibility. NASA has developed a disciplined process to match science needs and technologies that coalesce around notional mission concepts.

This paper summarizes is the most recent output from that process. The output has been organized by science focus area and notional mission concept, with science objectives, mission description, measurement strategy, and technology requirements identified for each notional mission concept. (Discussion of the variation across focus areas may be found in Stabnow [2]). The aggregation of these notional missions into time phase summary charts reflects only the order of technology readiness and approximate operating time for each mission; it does not reflect a science prioritization across focus areas or make any assumptions about budget availability.

\section{The Development Process}

Figure 1 shows how science roadmap information is translated into a matrix of science objectives, and a list of potential measurements and missions.

\footnotetext{
${ }^{1}$ U.S. Government work not protected by U.S. copyright.

${ }^{2}$ IEEEAC Panel 14.08, paper \#1, Version 5, Updated January 27, 2005
} 


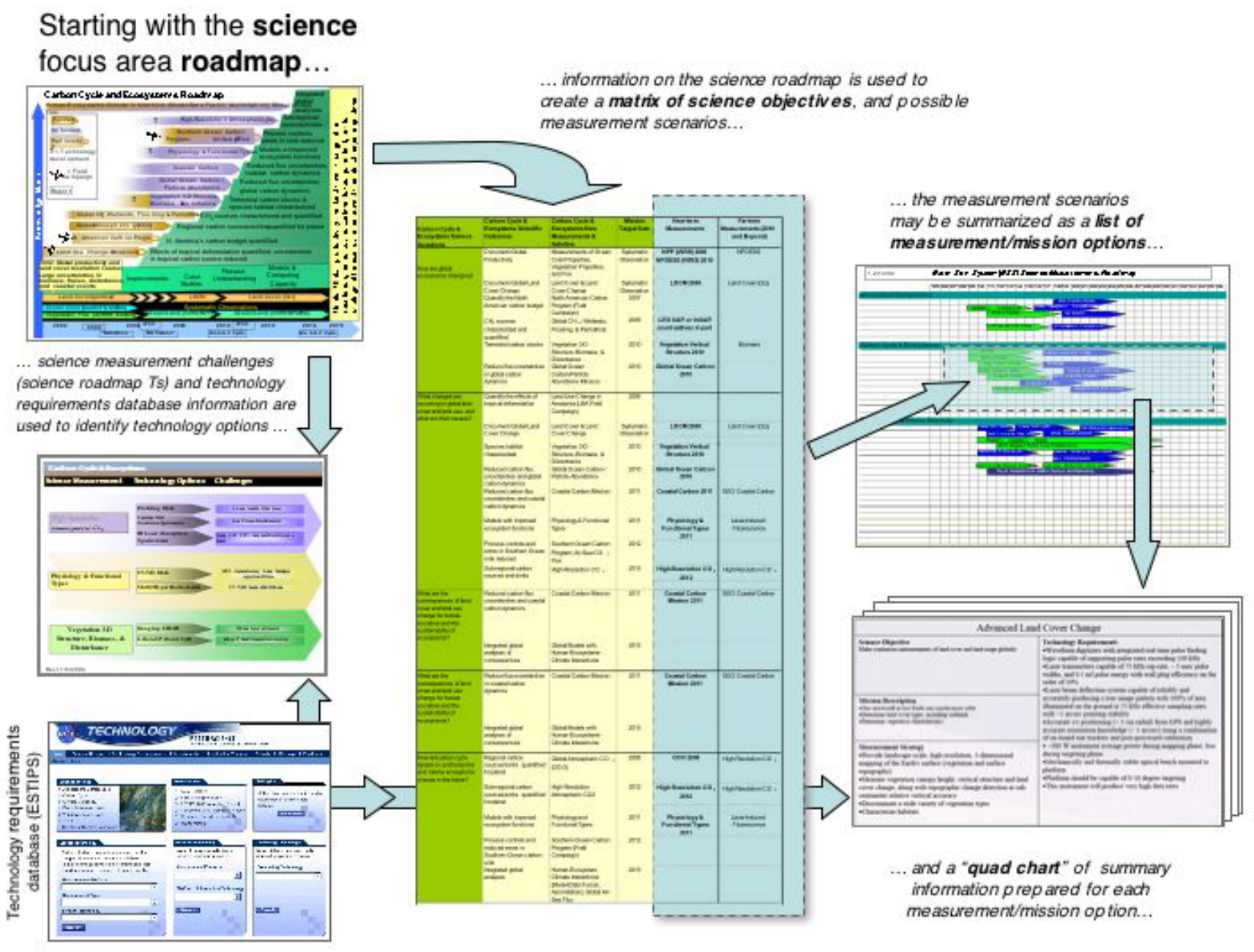

Figure 1 - The Development Process

The process starts with a science focus area roadmap. Roadmaps summarize the technology, observations, modeling, field campaigns, basic research, and partnerships needed over time to achieve the long-term goals for each focus area. Each roadmap diagram portrays a strategy for a decade of progress from "where we are now" toward a goal of "where we want to be" in 2015. This strategy has at its base a foundation of systematic observations and steady improvements in understanding and modeling capabilities. Specific programmatic elements, representing major investments of resources, are layered on top of this foundation. Focus area programmatic elements, indicated by the horizontal arrows within the roadmap, represent new activities that will greatly increase knowledge beyond that which would be derived from just continuing the analysis of the systematic observations. A " $T$ " icon means that technology development is required prior to undertaking an element.
Information on the science roadmap is used to create a matrix of science objectives and possible measurement scenarios, shown in the center of Figure 1. Information in the first four columns of the matrix is drawn directly from the science roadmap: key science questions are listed in the first column; and for each question a set of specific scientific outcomes, new measurements and activities, and proposed target dates are listed in the next three columns. Near-term measurements (prior to 2015) often have more detailed information available. Far-term measurements (beyond 2015) are more notional.

These measurement options may be summarized in an option list, as indicated in the upper right portion of Figure 1. Once again, it is important to note that the aggregation of these notional missions into time phase summary charts reflects only the order of technology readiness and approximate operating time for each mission; it does not reflect a science prioritization across focus areas or make any assumptions about budget availability. 
Given these measurement options, the next step is to develop summary information (a "quad chart") on the potential measurement or mission option. The Earth-Sun System Technology program has developed a database to support translating these options into potential technology needs [3]. The database includes capabilities for:

- Tracking science requirements;

- Identifying possible measurement scenarios to satisfy the science requirements;

- Identifying sensor and platform technology options for each of the measurement scenarios;

- Identifying technology capability needs for each of the technology options;

- Documenting heritage and state of the art for each of the needed technology capabilities; and

- Tracking current and past program technology investments and projected infusions to aid the technology infusion process.

Once scientific measurements have been articulated, it is possible to identify a wide variety of possible options for acquiring these measurements. Among the many active, passive, in situ and/or orbiting possibilities, some will have more developed technology than others. The ESTIPS database keeps track of these technology options and investments, and allows technology managers to identify technology areas which may benefit from further study and investment.

Additional discussion of the process for translating science objectives into technology options and key challenges may be found in Stabnow [2].

\section{RESULTS}

A list of measurement options for all seven of the EarthSun System science focus areas may be found in Figure 2. Three science focus areas (Atmospheric Composition, Carbon Cycle and Ecosystems, and Earth Surfaces and Interior Structure) appear in the top chart; a second set of three focus areas (Climate Variability and Change, Water and Energy Cycle, and Weather) appear on the second chart, and the final panel includes missions and measurements for the Sun-Solar System science focus area.

Green arrows indicate the nearer-term missions, and tan arrows indicate international activities. The longer range, notional activities are shown in blue; these are potential future missions that require technology development, and the names listed tend to be the geophysical measurements.
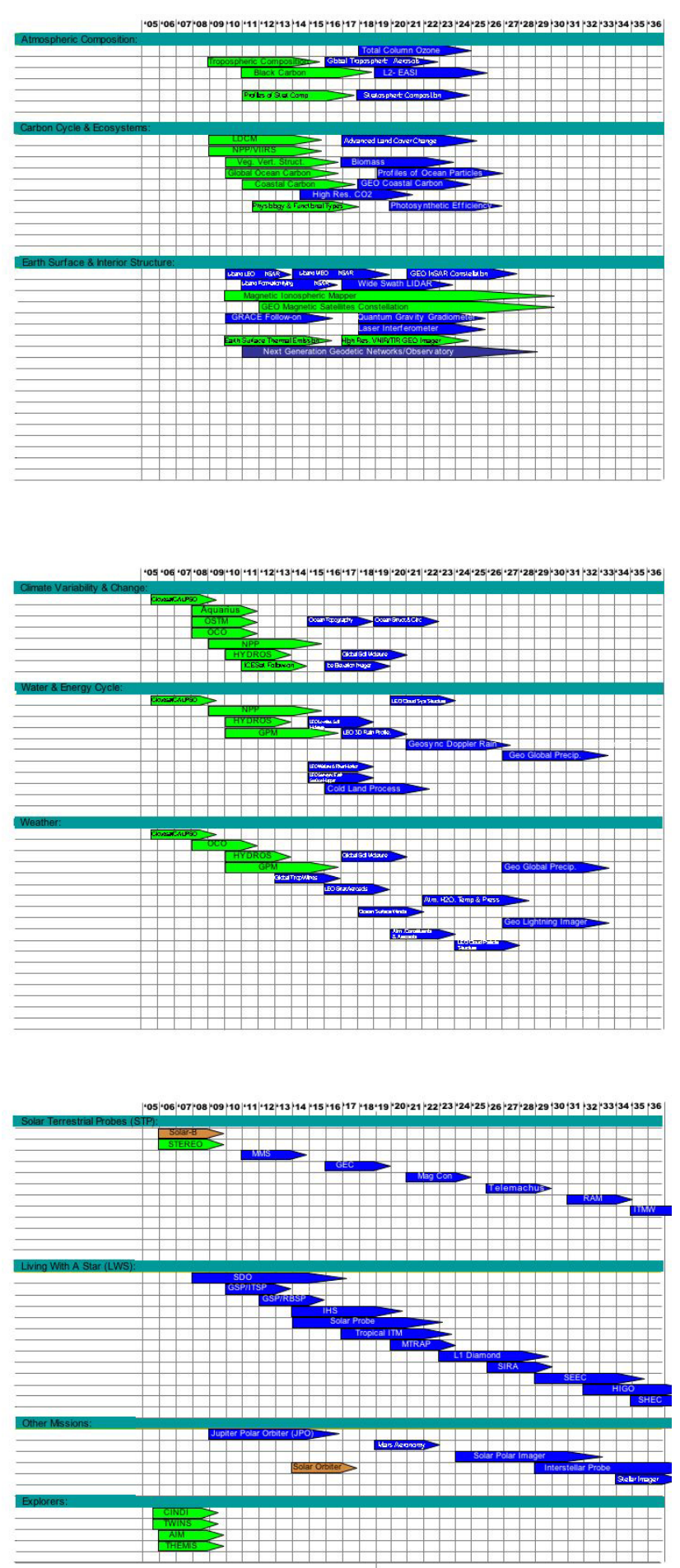

Figure 2 - Earth-Sun System Notional Science Measurements 


\section{Conclusions}

This paper describes the process used to develop a notional set of science objectives, technology requirements, and measurement/mission concepts stretching beyond the time horizon of current plans.

In the early months of 2005, several NASA road-mapping teams are being formed to create a coordinated and comprehensive longitudinal strategy, with key achievements, options, and decision points identified, to provide a foundation for NASA's long-term priorities and investments. The notional missions and measurements outlined in this paper can provide a starting point for discussions of needs and priorities.

The notional missions and measurements listed in this paper are not an agreed-upon mission set and timeline; they simply indicate the science requirements technology can enable. However, they will give the NASA roadmapping teams a good basis for scenario building. The materials can be a valuable resource in efforts to sketch out the future of Earth-Sun science and applications from space.

\section{REFERENCES}

[1] National Aeronautics and Space Administration, EarthSun System Research Plan. Draft: January 6, 2005.

[2] Willam Stabnow, "Deriving Technology Needs from Measurement Strategies," 2005 IEEE Aerospace Conference, Big Sky, Montana: Panel 14.08, Paper \#2.

[3] Earth-Sun System Technology Integrated Planning System (ESTIPS). See http://esto.nasa.gov/estips for further information.

\section{BIOGRAPHY}

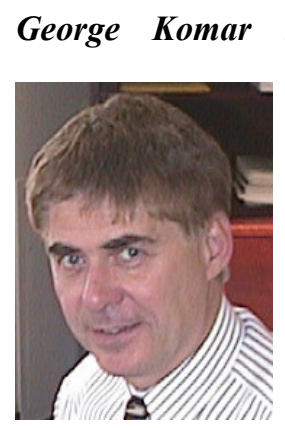

is Manager of Earth-Sun system technology for NASA's Science Mission Directorate. He joined the NASA science organization in 1998, when he was asked to create a science-driven technology program based on competitive selection. Since inception, technologies developed through the program -- a portfolio of more than 400 investments at over 70 institutions nationwide, including advancements in sensors, instruments, communication systems, and computer modeling -- have already been incorporated into numerous Earth and space science missions as well as commercial applications. In recognition of his innovative leadership of the technology program, George Komar received the NASA Medal for Exceptional Achievement in August 2000.

Amy Walton is Deputy Manager of the Earth-Sun system

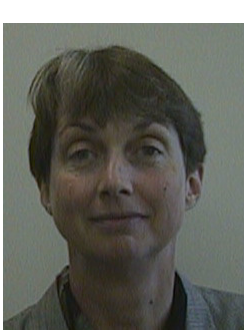
technology program. She previously directed a series of research programs at NASA's Jet Propulsion Laboratory in Pasadena, California, developing advanced capabilities for both earth and space science applications. While at the National Science Foundation she was Principal Investigator for a study of research management at the top 100 universities in the United States, and managed several projects on innovation, productivity improvement, and the contributions of small businesses to job generation. She has a Ph.D. from Princeton University.

\section{ACKNOWLEDGMENTS}

Many thanks to our colleagues in the Earth-Sun System Technology program, for contributions to the development of this paper. We are also grateful to the researchers associated with this program: your efforts have created a "family album" of innovations and accomplishments of which we are justifiably proud. 